\title{
REFLEXÕES SOBRE A SEXUALIDADE VELADA NO SILÊNCIO DOS CORPOS
}

\section{THE SEXUALITY COVERDED BY THE BODIES SILENCE}

\author{
Lúcia Beatriz Ressel* \\ Maria Júlia Paes da Silva**
}

RESSEL, LB; SILVA, MJP. Reflexões sobre a sexualidade velada no silêncio dos corpos. Rev Esc Enf USP, v. 35, n. 2, p. 150-4, jun. 2001.

\section{RESUMO}

As relações humanas são mediadas pela comunicação verbal e não-verbal. A comunicação não-verbal expressa nossos sentimentos e emoções, complementa, contradiz e substitui a comunicação verbal. Este artigo é uma reflexão que permeia a questão da comunicação não-verbal na abordagem específica da sexualidade, a qual se encontra velada no silêncio dos corpos e que expressa os sentimentos que resultam do processo interrelacional de cada vivência. Os dados foram coletados através de entrevistas individuais no periodo de janeiro a março de 1995, com mulheres de uma região rural do interior do Rio Grande do Sul. São apresentados, neste trabalho, sinais não-verbais da paralinguagem, cinésica (linguagem do corpo), tacêsica (linguagem do toque) e roupas e artefatos que demonstram a cultura, os valores e os preconceitos culturais sobre o tema sexualidade.

PALAVRAS-CHAVE: Comunicação não-verbal. Cultura. Sexualidade.

\begin{abstract}
The humane relations are mediated by the verbal and non-verbal communication. The non-verbal communication expresses our feelings and emotions, it complements, contradicts and replaces the verbal communication. This study reflects upon the non-verbal communication as an especific approach to sexuality covered by the bodies silence and it expresses the feelings which are determinated by the interrelation process of each experience. The data were colected through individual enterviews realized from January to March by the year 1995, according to the women from a countryside area in Rio Grande do Sul. It is included in this study the non-verbal signs of the "paralanguage", body language, touch language, and also clothes and items demonstrating the culture, value and cultural precoceptions about Sexuality.
\end{abstract}

KEYWORDS: Nonverbal communication. Culture. Sexualiti.

\section{INTRODUÇÃO}

Todas as relações humanas são mediadas pela comunicação, através de um ato interativo, criativo e envolvente, como refere BIRDWHISTELL (1970).

A comunicação inclui todas as formas de expressão e, de acordo com estudos da psicologia social, citados por SILVA (1996), estas expressões se dão através da comunicação verbal, por meio das palavras, em apenas $7 \%$, sendo as demais $93 \%$ expressas através da comunicação não-verbal, pelos sinais para- lingüísticos, 38\%, tais como a entonação da voz, os grunhidos, os ruídos vocálicos de hesitação, a pronúncia, a tosse e o suspiro provocados por tensão; e pelos sinais silenciosos do corpo, $55 \%$, como os gestos, o olhar, a postura, a expressão facial, assim como as próprias características fisicas, singulares a cada indivíduo e, que, por si só, falam a respeito de cada ser, individualizando-o dentro de seu contexto específico.

Enfermeira Doutoranda do Programa Interunidades de Doutoramento em Enfermagem da Escola de Enfermagem da Universidade de São Paulo. e-mail: giltimm@ct.ufsm

** Enfermeira. Professora associada da EEUSP. Livre Docente do Departamento de Enfermagem Médico-Cirúrgica, da Escola de Enfermagem da Universidade de São Paulo. E-mail; juliaps@usp.br. 
A comunicação não-verbal expressa nossos sentimentos e emoções, complementa, contradiz e substitui a comunicação verbal. Neste sentido, trazemos neste artigo uma reflexão que permeia a questão da comunicação não-verbal na abordagem específica da sexualidade, a qual se encontra velada no silêncio dos corpos e, neste silêncio, expressa os sentimentos e as emoções que resultam do processo interrelacional de cada vivência.

Nossos corpos, embora silenciosos, gritam a todo momento, emitindo mensagens acerca de seus valores, emoções, sentimentos, preconceitos, agrados e desagrados, expectativas, medos, inseguranças...Eles revelam uma vivência singular que, ao se entregar aos nossos cuidados, muitas vezes, perdem sua identidade única, porque os generalizamos, condenando-os a uma passividade nas relações, reduzindoos a um número, a um caso clínico, a uma ferida, a uma lesão...

No entanto, estes corpos reagem, demonstrando, na sua expressão facial, o medo, a dor, a insegurança, a insatisfação e todos os demais sentimentos por ele vivenciados. Ele pode, através da postura, explicitar sua aceitação ou negação ao nosso cuidado mostrando-se retraído ou aberto no processo de interrelacionamento que se dá na comunicação. Pode, também, pelo olhar, demonstrar sua insegurança, seu desejo de afeto, de ser tocado ou não, de receber mais atenção, se está concordando ou não com nossos cuidados (SILVA, 1998a).

Todas as expressões e os movimentos corporais são carregados de significados específicos dentro do contexto, do tempo e do espaço em que acontecem. Assim, como, também toda expressão facial e postura corporal atendem a um modelo cultural onde se dá o movimento do corpo (BIRDWHISTELL, 1970; HALL, 1986).

O corpo é um centro de informações para nós mesmos, e assim como ele comunica informações específicas dos indivíduos (como crenças, valores, personalidade...), ele nos permite uma auto-avaliação constante e um auto-conhecimento dinâmico e continuo.

Neste artigo apresentamos alguns dados referentes a um trabalho de campo, realizado junto a um grupo de onze mulheres rurais, no interior do Rio Grande do Sul, onde foi pesquisada "A cultura como mediadora na sexualidade da mulher rural" (RESSEL, 1995). As entrevistas foram gravadas em tape e realizadas em janeiro, fevereiro e março de 1995.
Centramos as reflexões deste artigo na perspectiva da comunicação não-verbal, cujos sinais foram emitidos nas entrevistas individuais que foram vivenciadas com muita emoção e sentimento, uma vez que este tema é carregado de mitos e preconceitos, expressos veladamente na linguagem silenciosa do corpo (GAIARSA, 2000).

A participação das mulheres, no referido trabalho, deu-se livremente, de forma voluntária, após assinarem o termo de Consentimento Informado, concordando em participarem e garantindo o anonimato de suas respostas. Foi percebido, ao longo do mesmo, que a maioria das colaboradoras' buscava, neste momento, um espaço para refletir, dando asas às suas dúvidas, dificuldades, inseguranças e preconceitos.

Uma das autoras do trabalho registrava os sinais não-verbais emitidos que demonstravam sentimentos, complementação ou contradição do seu discurso (enquanto sua fala estava sendo gravada) a partir da classificação proposta por SILVA (1996). Completava o registro ao final de cada entrevista.

As premissas teóricas que são a base para essa compreensão são (SILVA, 1998b): $1^{\circ}$ a Enfermagem é um processo interpessoal; $2^{\circ}$ a comunicação é um processo de interação simbólica complexo; $3^{\circ}$ os signos não-verbais envolvem comportamentos corporais, espaciais e locais, passiveis de serem identificados; 42 os numerosos comportamentos não-verbais numa mensagem são inter-relacionados; $5^{\circ}$ os sinais nãoverbais servem a várias junções da interação, a saber: demonstração de sentimentos, complementação do verbal, contradição do verbal e substituição do verbal; $6^{\circ}$ os padrões de comunicação interpessoais são estabelecidos com base nas necessidades interpessoais, que envolvem emoções e papéis sociais; $7^{\circ}$ a comunicação interpessoal implica na apresentação do eu a outros e sua meta é maior entendimento entre os comunicadores envolvidos no processo; $8^{\circ} \mathrm{o}$ enfermeiro não pode negar ou ignorar a dimensão do não-verbal no desempenho das sua atividades.

\section{APRESENTAMOS OS SINAIS DO CORPO}

Um dos primeiros sinais emitidos nas entrevistas foi o silêncio ostensivo. Uma das colaboradoras, em especial, mantinha-se rigidamente em silêncio, respondendo com breves meneios de cabeça, afirmando ou negando sobre seu entendimento ao longo da conversa. Mantinha seus braços estendidos ao lado

colaboradoras: serão chamadas, assim, neste trabalho todas as entrevistadas. 
do corpo, suas mãos unidas e cruzadas, onde esfregava um pedaço do tecido da sua saia. Sua cabeça pendia levemente para a frente, voltada para baixo, assim como seu olhar. Ela olhava rapidamente para a entrevistadora, quando esta reforçava ou tentava ilustrar a conversa.

No começo, imaginamos não estar sendo clara suficientemente. A entrevistadora pensou, também, que aquela entrevista não serviria muito, pois "poucas palavras estavam sendo ditas". No entanto, após o término da conversa e das anotações subsequentes, percebemos a riqueza dos sinais não-verbais emitidos.

O próprio silêncio já expressava sua dificuldade de lidar com o assunto. Os breves meneios afirmativos e negativos apresentados refletiam seu.entendimento e regulavam a conversa, porém a sua limitação em expor verbalmente as respostas ficavam por conta da timidez, que era um reflexo de uma vivência permeada por valores morais e religiosos muito rígidos que impregnavam de medo e vergonha sua sexualidade (BACALARSKI, 1991; GAIARSA, 2000).

Suas mãos cruzadas, roçando um pedaço de sua roupa, era um gesto adaptativo, involuntário, que demonstrava sua ansiedade, tensão e insegurança (SILVA, 1996). Isso levou a entrevistadora a procurar validar sua mensagem, oportunizando um feedback, na busca dos motivos que estavam provocando a tensão. Neste momento, a colaboradora expôs que, embora tentasse falar sobre o tema (sexualidade), eralhe muito dificil, devido à sua formação cultural (BEAUVOIR, 1991).

Sua dificuldade em olhar para a entrevistadora, quando estava falando, também refletia sua timidez, no entanto, percebemos que, quando era a entrevistadora que falava, ela se esforçava para olhála, mostrando seu respeito e seu interesse em participar do trabalho, assim como demonstrava sua atenção na entrevista.

Uma outra situação de grande silêncio deu-se por conta do entendimento de "ignorante" e "bicho-domato", que uma das colaboradoras expressou dizendo que "na colônia você acaba nem sabendo conversar direito, e principalmente, as mulheres, que nunca têm tempo para uma leitura, para se preparar melhor".

Foi redobrado o cuidado nestas ocasiões para não forçar respostas, pois o próprio silêncio já era um espaço onde estavam expressas as emoções e os sentimentos, e que expressam muito da nossa sexualidade (BACALARSKI, 1991).

Percebemos, na grande maioria das colaboradoras, gestos mais tensos como cruzar os braços, desviar o olhar, olhar para baixo, no início da entrevista (geralmente entre os 10 a 15 minutos iniciais), após o que iam relaxando, e naturalmente se "desarmavam", participando cada qual na sua maneira singular, sendo essa uma característica comum no início da entrevista.

Um outro sinal muito expressivo deu-se, quando uma das colaboradoras, entremeando um riso nervoso e curto, associado ao olhar desviado constantemente, de repente explodiu num choro, deixando fluir essas emoções, sua tensão e dificuldades de vivenciar a sexualidade (RESSEL, 1995).

Essa manifestação (choro/riso nervoso) reflete o estado afetivo da pessoa e, universalmente, encontramos o mesmo significado em diferentes culturas (DARWIN, 2000).

Procuramos ouvi-la atentamente, endereçandolhe um olhar solidário, tocando de leve sua mão, a partir do que ela foi se acalmando e expondo suas idéias com mais tranqüilidade (SILVA, 1996).

É importante salientar que, durante o processo da entrevista, a entrevistadora procurava limitar seus comentários e orientações para evitar induzir respostas, no entanto, este momento, por si só, já proporcionava um espaço de expressão de cada uma das mulheres participantes e era aguardado com ansiedade por elas, devido a forma velada e, muitas vezes, constrangida de vivenciar sua sexualidade, que não se expõe publicamente e requer outras formas de expressão e compreensão.

Com outra colaboradora os sinais do corpo eram carregados de preconceitos e preocupação com o controle social da comunidade. Sua entonação de voz diminuía, quando expressava uma informação que desaprovava e ia contra seus principios morais, e elevase quando queria reforçar, aprovando certo comportamento. Conjuntamente, arregalava os olhos ou contraía suas sobrancelhas, confirmando, na sua expressão facial, todos os seus valores, assim como franzia os lábios demonstrando desagrado e dúvida que contrariavam suas concepções.

Muitas vezes, a fala dessa colaboradora expressava o contrário de seus gestos e sinais, mostrando uma das funções da comunicação nãoverbal, que é contradizer o verbal, e que o não-verbal dificilmente pode ser escondido. Como refere GAIARSA (2000) podemos não querer vê-lo ou estar desatento, mas que ele existe e se manifesta, é real.

Percebemos que essa colaboradora tentava, através da fala, mostrar modernidade, e que não era preconceituosa, no entanto, suas expressões nãoverbais estavam carregadas de preconceitos e controle social. E, assim, constantemente, ela se contradizia no demonstrar suas emoções: mantinha o corpo enrijecido, fazia movimentos bruscos, pernas cruzadas e bastante fechadas... 
Outra expressão indicativa do controle do corpo deu-se através das roupas usadas por estas mulheres. Elas cuidavam para que a vestimenta não significasse ousadia e não expressasse sua sensualidade, combinando camisetas (largas), calças compridas (que não marcassem as roupas intimas), vestidos (sem decotes) e bermudas (na altura dos joelhos). Entretanto, muitas referiram gostar de se maquiar e colocar uma roupa nova, mas em ocasiões especiais, o que lhes dava muito prazer e refletia o seu sentido de feminilidade.

Em um dos primeiros contatos da entrevistadora com este grupo de mulheres foi recomendado por uma delas, líder no grupo, que "evitasse usar vestidos curtos ou roupas que expusesse o seu corpo, enquanto permanecesse na comunidade (embora estivesse em pleno verão), pois poderia ser mal interpretada".

Em algumas ocasiões, as colaboradoras referiram situações onde as práticas corporais e o controle do corpo eram desenvolvidos por meio de códigos e normas sociais internos ao grupo, conforme refere também BEAUVOIR (1991), como exemplificamos nas falas seguintes:

"Aqui... não pode expor o teu corpo. Se comprar uma mini-saia, já está feita a bronca. O pessoal não gosta disso". E, "uma vez, numa excursão, estava muito quente, e tinha uma senhora, também daqui, com uma blusinha de crochê, daquelas toda furadinha, mas com um trabalhado na altura dos seios... não tinha nada de ruim nela... e ela falou: Eu vou aproveitar prá botar aqui, que em casa meu marido não deixa, que o pessoal pode comentar".

Da mesma forma, as expressões de afeto e carinho em público, pelo casal, inclusive e, principalmente, quando casados, também era um indicativo do controle social do grupo, sendo causa de preconceito e levando a uma relação bastante discreta, quando em público.

Nas festas, reuniões e até na missa, os casais permaneciam separados, em grupos distin-tos (homens/ mulheres) e evitavam contatos mais intimos (como um abraço, um beijo...), como se estivessem "respeitando" o público, sendo o carinho pertencente ao domínio da intimidade, devendo existir somente na privacidade.

Essa postura e comportamento social são características relacionadas profundamente à formação cultural da comunidade onde se deu este estudo, na qual a etnia predominante era a de descendentes de italianos, e onde os valores morais e religiosos eram ainda muito rigorosos (HALL, 1986).
No mesmo sentido, a limitação do espaço da própria comunidade e sua peculiar história de formação proporcionou o controle social de seus membros, principalmente, junto ao cotidiano feminino, sua participação social e o uso de seu corpo (RESSEL, 1995).

Outro sinal não-verbal encontrado foi a postura corporal encolhida e introjetada que ocorria, quando a fala se referia ao constrangimento da relação sexual não desejada, mas consentida por parte das mulheres. E, segundo o entendimento delas, era uma "obrigação" dentro do casamento para as mulheres e uma "necessidade fisiológica" para os homens. Assim sendo, elas tinham que "atendê-los", até porque, se assim não fosse, corriam o risco de que eles procurassem "por isso" fora de casa.

Essa postura associou-se ao desvio do olhar, olhar para baixo, mãos cruzadas sobre o colo, que expressavam um sentimento de vergonha, desagrado, timidez, baixa auto-estima e dificuldades para relacionar-se e exercitar sua sexualidade, conforme já referimos anteriormente (SILVA, 1996).

O suor, o rubor, a palidez, o olhar arregalado, o franzimento dos lábios, o arquear das sobrancelhas, a contração da face, e outros sinais e gestos significativos de surpresa, desagrado, aprovação, alegria, nervosismo, vergonha, tensão, emoção... foram ao longo das conversas se intercalando, e dando a devida expressão ao verbalizado, ou ao não-verbalizado e, finalmente, um último gesto significativo de muita emoção que o tema da sexualidade suscita e apareceu nestas colaboradoras, foi o toque das mãos na altura do coração, que foi repetido várias vezes, associado aos gestos anteriormente descritos. Sabemos que "tocar nosso coração" é tocar nosso "eu" mais profundo, o local onde nos identificamos como sendo "eu", quando falamos de nós, de uma maneira não-verbal. Essa é uma marca da essência humana que há em nós; nossa sexualidade reflete toda a expressão emocional de nossa vivência, logo é comum encontrarmos a validação desse sentimento em nossos gestos involuntários (SILVA, 1996,1998b).

\section{CONSIDERAÇÕES FINAIS}

Nossa comunicação com as pessoas se dá a nível de tudo que percebemos, tendo um significado especifico a cada contexto, a cada vivência que é singular, que influencia e é influenciada pelo grupo social em que vivemos, como foi o caso do estudo referido neste artigo.

O nosso corpo emite, a todo momento, sinais não-verbais que são mensagens importantes, havendo necessidade de treinarmos nossa observação cada vez 
mais, melhorando nosso relacionamento interpessoal, e oportunizando um cuidado mais efetivo.

Os sinais do corpo nos falam muito da essência de cada ser humano, sendo uma linguagem silenciosa, cheia de mensagens. Estes sinais permitem também nosso auto-conhecimento e uma reavaliação constante do nosso significado de viver, e através da revisão dos nossos gestos, expressões, postura, olhar e características pessoais podemos reaprender continuamente a ver, a sentir, a ouvir e, a expressar, melhorando também nossa vivência.

Desenvolvendo nossa atenção aos sinais nãoverbais do corpo, ampliamos nossos canais de percepção e proporcionamos uma melhor rede de interação, facultando uma vivência mais saudável e, portanto, ...mais feliz.

Evoluímos muito tecnicamente enquanto enfermeiros, mas como técnica não significa ética, não conseguimos manter nossa humanidade nas pequenas coisas: esquecemos de sorrir, de olhar nos olhos dos nossos pacientes e de nossos companheiros de trabalho, de apertar as mãos, de fazer um afago, de puxar a cadeira, sentar e ouvir.

Fazer Enfermagem de uma determinada maneira é um reflexo das próprias crenças, sentimentos, pensamentos e conhecimentos, enquanto pessoa. Não é ético fazer ciência sem que haja consciência. Redescobrir o corpo, percebê-lo, reconhecer sua força e sua mensagem (explicita/velada!), para através desse corpo conhecido, consciente, ter contato com a realidade ao cuidar, diminui vários focos de conflito.

\section{REFERENCIAS BIBLIOGRÁFICAS}

BACALARSKI, MC. Algumas funções do silêncio. São Paulo, 1991, 152 p. Dissertação (Mestrado) - Faculdade de Filosofia, Letras e Ciências Humanas, Universidade de São Paulo.

BEAUVOIR, S de. O segundo sexo. 8.ed. Rio de Janeiro: Nova Fronteira, 1991.

BIRDWHISTELL, RL. Kinesics and context. Philadelfhia:

Pensylvania Press, 1970.

DARWIN, C. A expressão das emoções no homem e nos animais. São Paulo: Cia das Letras, 2000.

GAIARSA, JA. O olhar. São Paulo: Gente, 2000.

HALL, EA. A dimensão oculta. Lisboa: Relógio d'Água, 1986.

RESSEL, LB. A cultura como mediadora na sexualidade da mulher rural. Santa Maria, 1995. Dissertação (Mestrado) - Curso de Pós-Graduação em Extensão Rural, Universidade Federal de Santa Maria.

SILVA, MJP da. Comunicação tem remédio - a comunicação nas relações ínterpessoais em saúde. São Paulo: Gente, 1996.

Reflexões sobre a relação interpessoal no cuidar: o fator corpo entre a enfermeira e o paciente. In: MEYER, DE; WALDOW, VR; LOPES, MJM. Marcas da diversidade: saberes e fazeres da enfermagem contemporânea. Porto Alegre: Artes Médicas, 1998. Cap.7: 127-36. (a)

SILVA, MJP da. Análise comparativa da aplicação de um programa sobre comunicacão não-verbal para enfermeiros hospitalares - São Paulo, 1998. 104p. Tese (Lívre Docêncía) - Escola de Enfermagem, Universidade de São Paulo (b).

Artigo recebido em 20/07/00

Artigo aprovado em 14/09/01 